\title{
Does Obesity Affect Occupational Status?-Empirical Test Based on CGSS Mixed Cross-Section Data
}

\author{
Juanjuan Chen \\ The Glorious Sun School of Business and Management \\ Donghua University \\ Shanghai, China \\ e-mail:15856606407@163.com
}

\author{
Hongyan Zhao \\ The Glorious Sun School of Business and Management \\ Donghua University \\ Shanghai, China \\ e-mail:13856604975@163.com
}

\author{
Xiaoli Yang* \\ College of Economics and Management \\ Shenyang Agricultural University \\ Shenyang, China \\ 15956621578@163.com
}

\begin{abstract}
Obesity is an important public health concern, and may has an effect on workers' income, occupational status and labor supply. This study examines data from the Chinese General Social Survey (CGSS), and discusses the direct effect, social capital effect, human capital effect and discrimination effect of obesity on occupational status. This paper uses the average BMI of different people from the same community as an instrument variable to account for endogenous concerns and measurement error. Analysis of the mechanism by which obesity affects individuals in high-level occupational status verifies the direct effect and social capital effect, but the human capital and discrimination effect were not verified. Furthermore, the final result showed that obesity has a significantly negative impact on individuals reaching a high-level occupational status. The negative impact of obesity on individuals with a high-level occupational status was a result of direct and social capital effects.
\end{abstract}

Keywords-obesity; occupational status; social capital; human capit; discrimination effect

\section{INTRODUCTION}

According to the data of Chinese Center for Disease Control and Prevention, the percentage of the average BMI of Chinese adults grew from 21.7 in 1991 to almost 23.5 by 2011 and it is estimated that the average BMI of Chinese adults will reach 25.2 by 2031. In China, 46 million adults are obese and 300 million are overweight. Obesity not only leads to an increase in the disease rates, but also affects the income, occupational status and labor supply of workers. In the Chinese labor market, the phenomenon of discrimination due to appearance is gradually increasing. Enterprises in the recruitment process will set requirements on the appearance and body shape of candidates. Some enterprises think that the image of employees represents the image of enterprises. A good appearance may enhance candidates' competitive advantage and employment opportunities. Hence, this paper attempts to prove the influence of individual BMI on occupational status, and provide empirical evidence for the issue of appearance discrimination in China's labor market.

Prior studies have found that obesity affects the ability of workers to get jobs in two major ways. One way is that obesity affects health, thus affecting their employment. Since obesity is a symbol of unhealthiness, it could lead to acute and chronic diseases, such as hypertension and diabetes. Hence, from the perspective of healthy human capital, a decline in health will have many unfavorable consequences, such as decreasing labor time, reducing labor efficiency, or affecting the human capital of an individual, which results in influencing employment. Another consequence is that obesity influences emotional perceptions; this emotional awareness may come from individual aesthetics of the body and thus could lead to preferences for a certain kind of body shape or discrimination.

\section{THEORETICAL ANALYSIS}

Obesity can be seen as an unhealthy symbol, which has a negative impact on individuals reaching a high occupational status. Prior research has provided evidence that obesity is an important cause of high blood pressure, diabetes and other diseases. Obesity has a negative impact on personal heath. Prior studies have shown that individuals' health practices influence labor supply and work time, thus affecting their economic status[1]. In addition, an unhealthy body may lead to many negative effects, such as decreased operational efficiency and quality of work, affecting their ability to study or leading to employment discrimination; these effects may limit job or promotion opportunities. Because an individual's body is related to their labor ability, cognitive ability and noncognitive ability, this could explain why obesity could influence occupational types. Relevant research has provided evidence that overweight or obese staff may be seen to lack leadership. Overall, the negative appearance signal of obesity affects employees in high-level occupational status; thus, this paper sees this mechanism of action as a direct effect.

This study was supported by National Natural Science Foundation of China (No.71273177)(No.71373163) 
Second, BMI as a measure of an individual's body shape affects the accumulation of social capital and thus has an indirect impact on occupational status. In China, social capital is particularly important to achieve career promotions. Relying on the provision of social capital and the way of transmitting information, it significantly affects individual career mobility[2]. The literature has also claim that weight, height and other appearance characteristics have significant influences on the social network of employees and that there is a beauty premium in social network construction and social capital accumulation. In addition, some persons may choose friends based on appearance characteristics; thus, they can acquire emotional support through social psychological processes. Hence, obese persons may be vulnerable to the exclusion of neighbors and may have fewer opportunities to cooperate and communicate with others, affecting the accumulation of their social capital. Meanwhile, individuals with good body shapes will actively participate in social life and thus increase their stock of social capital. This paper refers to this mechanism of action as the social capital effect.

Furthermore, BMI has a significant impact on human capital accumulation. In a more recent study provided evidence that obese employees may lose training or employment opportunities due to relatively inconvenient exercise, which affects their work experience accumulation. In addition, health is an important component of human capital, and health mainly includes physical health and mental health. First, discrimination of obesity may bring about many passive consequences, such as affecting an individual's self-esteem, reducing their self-identity or self-efficacy, and decreasing happiness. The other research perspective is that weight discrimination may increase personal negative emotions. Previous studies have also confirmed that there is a positive correlation between weight and depression. One area of research examines the impact of human capital on the movement of occupational status, providing evidence of a positive relationship. Therefore, this paper refers to this mechanism of action as the human capital effect.

In addition, obesity can lead to discrimination in the labor market, which affects employees' occupational status. In the recruitment process, enterprises will set the requirements for staffs' appearance. Those who are overweight or obese have more difficulty getting interview opportunities than those who are average in weight, and they can also be considered unqualified for work[3]. Employees who are overweight are often mistakenly regarded to lack self-control and enthusiasm, or some companies may have appearance preferences that question the abilities of overweight or obese employees[4].
Based on the above content, this paper calls this mechanism of action the discrimination effect.

It is worth mentioning that occupational status may also have an impact on personal BMI. In the United States, administrators find it easier to maintain a healthy weight, since they can purchase healthier food and enjoy fitness services. Thus, they have more health knowledge to maintain a standard body. In contrast, people at the bottom of society more easily gain weight, since they cannot afford the high price of healthy foods. However, in contrast to the abundant literature on western societies, Chinese scholars have found that the position of administrator has a significantly positive impact on BMI. In China, administrators have more health knowledge and financial ability, but they need to cope with more 'night banquet' activities, which lead to high calorie intake[5].

\section{DATA SOURCES AND SAMPLE STATISTICS}

\section{A. Model specification and identification}

In this paper, we examined the impact of obesity on occupational status using the 2010, 2012, 2013, and 2015 China General Social Surveys. The CGSS is the Chinese version of the General Social Survey, and it aims to track social development in China. It is jointly conducted by the Renmin University of China and the Hong Kong University of Science and Technology. Currently, there are night waves of CGSS published, and each wave is a cross-sectional database. Considering the timeliness of the research content and because the 2011 wave has many omitted values, we used waves from 2010, 2012, 2013, and 2015.

This paper's primary research question concerns how obesity affects personal occupational status. We excluded observations that were engaged in agricultural work because agricultural work does not involve personal occupational status. We also deleted observations from samples that do not belong to being employed. Further, we deleted observations with ages older than 60 years and below 16 years to ensure that respondents can conform to the legal working age in China. We also excluded all observations with missing values for the dependent or explanatory variables. This resulted in 9,396 remaining values. Of these 9,396 respondents, 2,883 observations were in high-level occupational status and 6,513 were otherwise. The obesity measure, the explanatory variable of interest, was derived from BMI, which was calculated by dividing weight in $\mathrm{kg}$ by height in meters squared $(\mathrm{kg} / \mathrm{m} 2)$ because BMI is a suitable measure of height-adjusted weight. TABLE I provides descriptive statistics for all variables.

TABLE I. SUMMARY STATISTICS

\begin{tabular}{|c|c|}
\hline Variable & Definition \\
\hline Dependent variable & \\
\hline Occupational status & $=1$ if the respondent be in a high level of occupational status, 0 otherwise \\
\hline Independent variable & Dividing weight in $\mathrm{kg}$ by height in meters squared $\left(\mathrm{kg} / \mathrm{m}^{2}\right)$ \\
\hline BMI & \\
\hline Individual characteristics & 1 to 5 means that the strength of contact with friends or relatives \\
\hline Social times & 1 to 5 means that the degree of depression \\
\hline Mental health & Height of the respondent $($ meter $)$ \\
\hline Height & $=1$ if the respondent is male, $=0$ otherwise \\
\hline Gender &
\end{tabular}




\begin{tabular}{|c|c|}
\hline \multicolumn{2}{|c|}{ Cont. to TABLE I } \\
\hline Education attainment & Years of education of the respondent \\
\hline Age & Age of the respondent(years) \\
\hline Marital status & $=1$ if the respondent is married, 0 otherwise \\
\hline Communist Party membership & $=1$ if the respondent is party member, 0 otherwise \\
\hline Hukou type & $=1$ if the Hukou type is urban Hukou, 0 otherwise \\
\hline Mandarin attainment & $=1$ if the mandarin attainment is good, 0 otherwise \\
\hline Company type & $=1$ if company type is government institutions, $=2$ if company type is enterprises, 3 otherwise \\
\hline Family characteristics & \\
\hline Employment situation of father & $=1$ if the employment situation of father is employed, 0 otherwise \\
\hline Sample size & 9,396 \\
\hline
\end{tabular}

\section{RESUlTS AND ROBUSTNESS CHECKS}

\section{A. Model specification and identification}

To address the research question, this paper used the following Probit regression, which regressed the relationship between obesity and employees' occupational status, estimating the following regression model:

$$
\operatorname{Pr}\left(Y_{i t}=1\right)=G\left(\alpha+\beta M_{i t}+\gamma Z_{i t}+\delta_{i}+\lambda_{t}\right)
$$

where $\mathrm{Y}_{\text {it }}$ is a dummy variable equal to 1 for the whole (yearly) period if the employee is at a high-level occupational status and 0 otherwise. $\mathrm{BMI}_{\mathrm{it}}$ is a continuous variable, which is formed by dividing weight in $\mathrm{kg}$ by height in meters squared. $Z_{i t}$ is a vector of observed demographic and family variables $\sigma_{i}$ is the provincial fixed effects, and $\lambda_{t}$ is the annual fixed effects.

\section{B. Result discussion}

This paper first used a binary Probit regression model to examine the influence of BMI on occupational status. Then, we applied an instrumental variable Probit (IVProbit) regression to address endogeneity issues. To test the effect of social capital and human capital, we used 2SLS regression to correct the endogeneity issues. Furthermore, this paper used the question of whether staff has a fixed employer to test the discrimination effect, since the stability of work with employees who have a fixed employer is higher than that for those who have a nonfixed employer. Therefore, in terms of occupational status, employees with fixed employers are more likely to acquire a high-level occupational status than employees with nonfixed employers. Because the Wald test of the discrimination effect model shows that there were not significant endogeneity issues, we used the binary Probit regression model. The results are presented in Table II.

TABLE II. THE EFFECTS OF BMI ON INDIVIDUAL OCCUPATIONAL STATUS

\begin{tabular}{|c|c|c|c|c|c|c|}
\hline & Model 1 & Model 2 ( IV ) & $\begin{array}{c}\text { Model } 3 \\
\text { (IV) }\end{array}$ & $\begin{array}{l}\text { Model } 4 \\
\text { (IV) }\end{array}$ & Model 5 ( IV ) & Model 6 \\
\hline Variable & $\begin{array}{c}\text { Occupational } \\
\text { status }\end{array}$ & $\begin{array}{c}\text { Professional } \\
\text { status }\end{array}$ & Social capital & $\begin{array}{c}\text { Human } \\
\text { capital }\end{array}$ & $\begin{array}{c}\text { Occupational } \\
\text { status }\end{array}$ & $\begin{array}{c}\text { Whether there is a fixed } \\
\text { employer }\end{array}$ \\
\hline BMI & $0.011^{* *}$ & $-0.090 *$ & $-0.050^{*}$ & $0.110 * * *$ & $-0.087^{*}$ & $0.016^{* *}$ \\
\hline Social capital & - & - & - & - & $0.164 * * *$ & $0.074 * * *$ \\
\hline Human capital & - & - & - & - & -0.027 & -0.035 \\
\hline Height & $0.530 *$ & $0.537^{*}$ & 0.225 & $-0.755^{* * *}$ & $0.492 *$ & 0.736 \\
\hline Gender & $0.237 * * *$ & $0.393 * * *$ & $0.244 * * *$ & $0.155^{* * *}$ & $0.362 * * *$ & $-0.444 * * *$ \\
\hline Education attainment & $0.116^{* * *}$ & $0.113^{* * *}$ & $0.023^{* * *}$ & -0.006 & $0.111^{* * *}$ & $0.080^{* * *}$ \\
\hline Age & $0.067 * * *$ & $0.095 * * *$ & $-0.038 * * *$ & $0.054 * * *$ & $0.103^{* * *}$ & -0.027 \\
\hline Age2 & $-0.001 * * *$ & $-0.001^{* * *}$ & $0.000 * *$ & $-0.001 * * *$ & $-0.001 * * *$ & 0.000 \\
\hline Marital status & $0.140 * * *$ & $0.178^{* * *}$ & -0.023 & $-0.122 * * *$ & $0.180 * * *$ & $0.136^{*}$ \\
\hline $\begin{array}{c}\text { Communist Party } \\
\text { membership }\end{array}$ & $0.515 * * *$ & $0.540 * * *$ & $0.110^{* * *}$ & 0.010 & $0.526 * * *$ & $0.226^{* *}$ \\
\hline Hukou & 0.026 & 0.046 & $0.086 * * *$ & 0.026 & 0.035 & $0.239 * * *$ \\
\hline Mandarin attainment & $0.118^{* * *}$ & $0.124 * * *$ & $0.067 * * *$ & $-0.061 * * *$ & $0.112 * * *$ & $0.120 * *$ \\
\hline $\begin{array}{l}\text { Employment situation of } \\
\text { father }\end{array}$ & 0.050 & $0.066^{*}$ & $0.087 * * *$ & -0.029 & 0.051 & 0.064 \\
\hline Company & Yes & Yes & Yes & Yes & Yes & Yes \\
\hline Province & Yes & Yes & Yes & Yes & Yes & Yes \\
\hline Year & Yes & Yes & Yes & Yes & Yes & Yes \\
\hline Constant & $-386.2^{* * *}$ & $-401.6^{* * *}$ & $-47.87 * * *$ & -14.94 & $-397.7^{* * *}$ & -20.08 \\
\hline Obs. & 9396 & 9396 & 9396 & 9396 & 9396 & 9268 \\
\hline $\mathrm{R}^{2}$ & 0.1717 & 0.1457 & 0.084 & 0.1457 & 0.1459 & 0.3986 \\
\hline Wald test & - & $1599.2^{* * *}$ & $1143.7^{* * *}$ & $150.2 * * *$ & $1646.7^{* * *}$ & - \\
\hline Chi 2 (1) & - & $4.52 * *$ & $3.30 *$ & $11.65^{* * *}$ & $4.13^{* *}$ & - \\
\hline
\end{tabular}

Notes: '***', '**' and '*' refer to being statistically significant at the $1 \%, 5 \%$ and $10 \%$ levels, respectively. 'Other migration' means rate of the elders' migration of the others at the same sample point. 'Brother or

Regarding our control variable, we found that BMI had a significantly positive impact on individuals' occupational status. Considering the endogeneity issues, the first-stage results of the conventional IV estimation showed that the IV sister' means that whether the migrant population has brothers or sisters in their hometown. was significantly and positively correlated with BMI. This paper focuses on the second-stage results presented in Model 2. The coefficient of BMI in the IV-Probit was significantly negative, implying that rising BMI reduced the probability of 
employees reaching a high-level occupational status. As a comparison, Model 1 first shows the Probit results, and Model 2 presents the results from the conventional IV estimation. The model of BMI on individuals' occupational status has endogeneity issues. In addition, the coefficient of BMI in Model 5 was still significantly negative, indicating that BMI had a directly negative impact on individuals' occupational status. That is, the direct effect of BMI on an individual's occupational status was verified. In addition, according to the mediating effect method, the second step of the mediating effect model can be continued.

This paper further examined the effect of social capital. The results of Model 3 that as BMI increases, an individual's social capital decreases significantly. Since the coefficient of social capital in Model 5 was significantly positive, we continued the third step of the mediating effect method. The tests of $\mathrm{Z}$ values were all significant, indicating that the mediating effect of social capital is significant. Because the fourth test of $\mathrm{Z}$ values was also significant, there was a partial mediating effect, that is, the effect of social capital is verified.

To disentangle the mediating effect of human capital on individual occupational status, we re-ran the 2SLS regressions on a restricted sample of observation. The regression results are shown in Model 4. We can see that the coefficient of BMI in Model 4 is significantly positive; indicating that the level of individual psychological depression will improve with increased BMI. Although the coefficient of human capital in Model 5 was not statistically significant, we performed a Sobel test to verify the mediating effect of human capital. Finally, the Z-value is equal to 1.297 , and the $\mathrm{P}>0.10$, which was calculated by the Sobel test formula, implies that the mediating effect of human capital does not exist in the relationship between the BMI and an individual's occupational status. Therefore, the effect of human capital has not been verified.

The regression results of other control variables are shown in Model 5. Taller and male respondents tended to be in a higher level of occupational status. More highly educated respondents generally tended to be in a higher level of occupational status. In addition, respondents who were married and party members tended to be in a higher level of occupational status. Having better mandarin communication skills also increased the likelihood of respondents being in a high-level occupational status. Age showed a U-shaped relationship with high-level occupational status. As age increased, the probability of respondents being in a high-level occupational status first decreased and then increased.

The purpose of Model 6 is to test the effect of discrimination. The effect of discrimination is that individuals may be hindered by obesity in the process of promotion. To test this effect, the group of employees was divided into fixed employers and nonfixed employers. The regression results show that employees with higher BMI tended to have a fixed employer. Finally, the result is contrary to the effect of discrimination, perhaps because staff with nonfixed work was concentrated in the floating population. In China, most of the floating population is rural migrants who need to engage in hard work; thus, their BMI may not be high. Based on this, the regression results show that, as BMI increases, the probability of staff having a fixed employer increases. Therefore, the discrimination effect was not verified.

\section{CONCLUSION}

In this paper, we investigated the relationship between obesity and the level of occupational status among employees in China using a large representative survey. In particular, this paper constructed the mechanism by which obesity affects individuals' ability to reach high-level occupational status through the direct effect, social capital effect, human capital effect and discrimination effect. Then, we used the mediating effect model to test the social capital effect, human capital effect and discrimination effect. Meanwhile, we accounted for the endogenous problems in the model by using the average BMI of different people from the same community. We found that BMI had a significantly positive effect on individuals' ability to reach high-level occupational status when we used the Probit model; when the IV-Probit model was used for the regression, the result was reversed. Thus, the relationship between obesity and the level of occupational status has significant endogeneity problems.

Analysis of the mechanism by which obesity affects individuals in high-level occupational status verifies the direct effect and social capital effect, but the human capital and discrimination effect were not verified. Furthermore, the final result showed that obesity has a significantly negative impact on individuals reaching a high-level occupational status.

There may be two reasons for the result of obesity have negative impact on individuals with a high-level occupational status was a result of direct and social capital effects. First, as a symbol of unhealthiness, obesity may lower employees' energy levels to work, thus inhibiting the upward mobility of occupations. In addition, the labor market perhaps has higher health requirements for employees, and obese persons are therefore not competitive compared with healthy persons. Finally, because of appearance discrimination in social activities, individuals' social capital will be reduced. Since the beauty premium in social capital may lead to the unfair treatment of employees in the labor market, employees will not have a fair chance of promotion.

\section{REFERENCES}

[1] Xiao Zhou, Zhongyue Feng, Shan Sun "Can personal health investmen promote the employment-an empirical analysis based on CHNS," Population Journal, 2015,vol.21,pp.87-101.( In Chinese )

[2] Tianzhu Gu, Yueqing Ji "Beauty Premium in Social Capital-Empirical Research Based on Social Network of Labor Force with Appearance Differences,” Research Economics and Management,2017,vol.9,pp.74-83.( In Chinese )

[3] Kinge, J. "Body mass index and employment status: a new look," Economics \& Human Biology, 2016, vol.22, pp. 117-125.

[4] Qiuchuan Jiang, Kezhong Zhang "Economics of Beauty in China's Labor Market: Does STature Matter?” China Economic Quarterly,2013,vol.12, pp. 983-1006.( In Chinese )

[5] Guohua Ni, Fengtian Zheng "Health Hierarchy: the Study on the Cause of 'Diseases of Affluence' in the Context of Ubiquitous Obesity," China Soft Science,2014,vol.10, pp. 77-82.( In Chinese ) 